\title{
Survey of 'd'Anjou' Pear Metabolic Profile Following Harvest from Different Canopy Positions and Fruit Tissues
}

\author{
David R. Rudell \\ Tree Fruit Research Laboratory, Agricultural Research Service, U.S. \\ Department of Agriculture, Wenatchee, WA 98801
}

Sara Serra

Tree Fruit Research and Extension Center, Washington State University, Wenatchee, WA 98801

Nathanael Sullivan and James P. Mattheis

Tree Fruit Research Laboratory, Agricultural Research Service, U.S. Department of Agriculture, Wenatchee, WA 98801

\section{Stefano Musacchi ${ }^{1}$ \\ Tree Fruit Research and Extension Center, Washington State University, Wenatchee, WA 98801}

Additional index words. Pyrus communis, light exposure, canopy, metabolomics

\begin{abstract}
Physiological variability within a large canopy 'd'Anjou' tree results from agronomic and environmental factors. Fruit diversity within the canopy was surveyed using metabolic profiling to identify metabolism associated variability within the canopy. Different portions of the same fruit were evaluated to determine future precise sampling protocols for metabolic profiling of pear. We expected that the metabolic profile of the peel and cortex would be diverse and these differences would highlight specific metabolic pathways as influenced by these conditions. Another focus of this work was developing an untargeted metabolic profiling protocol tailored for pear using a combination of extractions coupled with GC-MS and LC-MS analysis. 'd'Anjou' pear fruit harvested from two different zones of trees trained to an open vase canopy were maintained at room temperature for $\mathbf{2 4}$ days to observe any changes in external phenotype and metabolic profile. Fruit harvested from the internal canopy were greener as also indicated by high Index of Absorbance Difference $\left(I_{A D}\right)$ and hue angle values. Metabolic profile differences between tree positions were widespread and included metabolites from many pathways beyond those associated with peel color. In addition, peel metabolic profile was different depending upon the tissue position (top vs. bottom) sampled from the pears. Specific pathways altered by tree position included those potentially linked to fruit quality and ripeness, including malic acid and aroma volatile (V) levels, as well as light environment, such as flavonol glycoside levels. Present results warrant further future work targeting these changes over time during storage and alongside fruit quality analyses to validate the impacts on ripening and tree factors. In addition, outcomes indicate tissue sampling strategies require consistency with respect to the region of the pear fruit sampled for metabolomics.
\end{abstract}

Open vase canopy architecture is common in low density pear orchards of the Pacific Northwest region of the United States. This system is used to manage vigorous varieties in the absence of dwarfing rootstocks (Neri et al., 2008; Zhang et al., 2016). Light penetration is variable in different zones of large canopy trees impacting bud differentiation, fruit set, fruit size, and fruit quality (Khemira et al., 1993). Light exposure can have a large influence on 'd'Anjou' quality and ripening (Kappel and Neilsen, 1994; Zhang et al., 2016). For instance, dry matter accumulation within the tree is a function of light interception and orchard design (Palmer, 1988; Wünsche et al., 1996). In apple, pear, avocado, and kiwifruit, the sunexposed side of fruit can be firmer at harvest than the shaded side (Raffo et al., 2011). High temperature and solar radiation together can also alter fruit quality in terms of external sunburn incidence and increased soluble solid content as reported in apple (Schrader et al., 2009; Torres et al., 2013). For example, sun-exposed 'Bartlett' pears before and after ripening at room temperature $\left(22{ }^{\circ} \mathrm{C}\right)$ had higher firmness than fruit grown in the shade (Raffo et al., 2011). However, high PAR does not necessarily confer higher sugar content in 'Bartlett' as high temperature can have a detrimental effect on assimilate translocation (Raffo et al., 2011).
As physiological change often results from altered metabolism, metabolic profiling is a powerful approach for understanding plant physiological reactions to biotic and abiotic stressors and/or environmental variation, such as alteration of nutrient or light regimes (Carreno-Quintero et al., 2013). Metabolomic response can precede transcriptome response to a change in plant growth environment (Caldana et al., 2011). Pear fruit has recently been the subject of reports where more comprehensive metabolic profiling was used to evaluate ripening. Metabolic profiling of 'La France' was used to track 250 primary and secondary metabolites during on-tree fruit development and ripening starting at 2 weeks before bloom until 1 month following harvest (Oikawa et al., 2015). 'La France' is an autumn cultivar that does not require chilling treatment but its application can stimulate the ripening process (Hiwasa et al., 2003). Other -omics approaches have also been used to evaluate different aspects of pear fruit ripening and quality, including proteomics (Pedreschi et al., 2009; Reuscher et al., 2016), transcriptomics (Nashima et al., 2013), and ionomics (Reuscher et al., 2014).

Metabolism can also differ in different plant tissues and also in fruit. For instance, levels of phenylpropanoids are different during fruit development between tomato peel and flesh (Moco et al., 2006). In mango, the distribution of aroma compounds was different among tissues with higher levels of Vs in the top and outer portions of the mesocarp (Lalel et al., 2003). In apple and peach, V content of the epidermis is higher than other fruit tissues (Aubert and Milhet, 2007; Guadagni et al., 1971). Levels of metabolites in 'Conference' pear subjected to low oxygen stress are unevenly distributed in the cortex, with a radial gradient, particularly of metabolites related to respiration that depend on $\mathrm{O}_{2}$ and $\mathrm{CO}_{2}$ in the tissue (Pedreschi et al., 2009). Untargeted metabolic profiling affords a relatively unbiased qualitative and quantitative estimation of the chemical composition of an organism for a more complete understanding of metabolism associated with environment or phenotype (Carreno-Quintero et al., 2013; Fiehn, 2002; Oms-Oliu et al., 2012). Strawberry fruit maturation and ripening investigated using this approach revealed the involvement of several biochemical pathways in nonclimacteric ripening (Zhang et al., 2010). During peach ripening, the role of amino acids and stored proteins in the early stage of peach development as substrates of the phenylpropanoid pathway and energy metabolism during climacteric ripening was identified (Lombardo et al., 2011). Other studies demonstrated that the metabolic profile, especially phenolics, vary during grape and raspberry development being influenced by genetics or environment (Ali et al., 2011; Oms-Oliu et al., 2012; Stewart et al., 2007).

Profiling of pear fruit Vs, nonpolar (NP), and polar metabolites was used to assess variability within pear metabolome. We employed this methodology to survey postharvest metabolic differences resulting from 
the tree position of where fruit resided during growth and also to better understand the degree to which the metabolome is variable from the top to bottom of the fruit. In the present study, we did not investigate the already established influence of tree position on pear maturity and quality recounted in introduction and discussion, but, instead, laid down the groundwork necessary for a more complete study of the impacts of tree position on metabolism throughout the supply chain. We expected that metabolic differences may reflect elements of light interception, microclimate, fruit development, and ripeness.

\section{Materials and Methods}

Fruit source, ripening assessment, and postharvest treatment. 'd'Anjou' pear fruit were harvested on 27 Sept. 2013 (commercial harvest for that year) from mature trees trained to an open vase from a commercial low density plating orchard in Cashmere, WA. Fruit were selected for similar size and absence of defects from two extreme canopy positions (15 fruit/position among several trees): external (top) and internal (bottom). Fruit size was similar, as average fruit height (H) was $96 \mathrm{~mm}$, equatorial width (W) $77 \mathrm{~mm}$, and $\mathrm{H} / \mathrm{W}$ ratio $1: 3$. Fruit weight and $\mathrm{I}_{\mathrm{AD}}$ index (Index of Absorbance Difference) were immediately assessed after harvest, and fruit were held at 20 to $25^{\circ} \mathrm{C}$ for $24 \mathrm{~d}(27 \% \mathrm{RH})$. $\mathrm{I}_{\mathrm{AD}}$ was evaluated using a DA-meter (Sinteleia, Bologna, Italy). The DA-meter is a portable Vis/NIR instrument that estimates chlorophyll content several millimeters into the outer mesocarp that usually decreases during maturity in a climacteric fruit by measuring the absorbance difference $\left(\mathrm{I}_{\mathrm{AD}}\right)$ between 670 and $720 \mathrm{~nm}$ (Ziosi et al., 2008). During the postharvest period, weight (twice in $24 \mathrm{~d}$ ) and $\mathrm{I}_{\mathrm{AD}}$ (seven readings in $24 \mathrm{~d}$ ) were measured as another assessment of relative maturity.

After $24 \mathrm{~d}$ of ripening (at 20 to $25^{\circ} \mathrm{C}$ ), background peel color of each fruit was evaluated using a Minolta colorimeter (Minolta

Received for publication 3 Aug. 2017. Accepted for publication 11 Sept. 2017.

This research was supported by PNW Pear Research Committee, project number: PR14-108AImproving quality and maturity consistency of 'd'Anjou'.

Any opinions, findings, conclusions, or recommendations expressed in this publication are those of the author(s) and do not necessarily reflect the view of the Washington State University and PNW Pear Research Committee.

D.R.R., S.S., N.S., J.P.M., and S.M. substantially contributed to the conception, design of the work, to the acquisition, analysis, or interpretation of data for the work; to drafting the work or revising it critically for important intellectual content; to final approval of the version to be published. All authors are in agreement to be accountable for all aspects of the work in ensuring that questions related to the accuracy or integrity of any part of the work are appropriately investigated and resolved.

${ }^{1}$ Corresponding author. E-mail: stefano.musacchi@ wsu.edu.
CR-300 Chroma meter; Konica Minolta, Tokyo, Japan) and recorded for each fruit as CIE L*a*b* color coordinates and reported as hue angle (actual color, $\mathrm{h}^{\circ}$ ) and chroma (intensity of color, C*) (McGuire, 1992; Núñez-Delicado et al., 2005). Ethylene production was measured from five replications of three fruit per canopy position. Fruit were sealed in glass jars $(3.7 \mathrm{~L})$ containing a rubber septum in the lid for $15 \mathrm{~min}$. A $0.5-\mathrm{mL}$ sample of headspace was drawn up using a $1-\mathrm{mL}$ plastic syringe with a $25 \mathrm{~mm}$ long needle piercing the septum and injected into the inlet of a 6890A GC (Hewlett Packard, Avondale, PA) equipped with a flame ionization detector and a stainless steel column $(450 \times 2 \mathrm{~mm}$ I.D. $)$ packed with $80 / 100$ mesh Poropak Q (Supelco, Bellafonte, PA). The instrument was calibrated using an authentic ethylene standard (Scotty Analyzed Gasses, Bellafonte, PA). $\mathrm{N}_{2}$ carrier gas, $\mathrm{H}_{2}$, and air flow rates were 1,30 , and $280 \mathrm{~mL} \cdot \mathrm{min}^{-1}$, respectively. Inlet, oven, and detector temperatures were adjusted to 100,60 , and $300{ }^{\circ} \mathrm{C}$, respectively. From the same jars, $\mathrm{CO}_{2}$ concentrations (\%) were estimated using a handheld gas analyzer (Mocon-Dansensor, Minneapolis, MN).

Tissue sampling and processing. Three fruits pooled together were considered a replicate. Within each canopy position (internal and external), five replicates for peel (two samples were lost, one from external/top and one from external/bottom resulting from poor analysis quality of one of the extraction/ instrumental methods), and five replicates for cortex were collected after 24 d of postharvest. Each tissue was sampled keeping separated 'top' (from stem-end region up to above the equatorial zone) and 'bottom' (below the equator in the calyx-end region) of the pear. Peel tissue was collected using a sharp fruit peeler, and "Peel top" and "Peel bottom" were immediately frozen in liquid nitrogen. Fruit flesh was cut from each area pooling together three wedges of peel-free cortex sampled outward of the core line, then finely diced. The core was discarded (Supplemental Fig. 5). "Cortex top" and "Cortex bottom" were frozen separately in liquid nitrogen. A total of 40 samples were collected [2 canopy positions (external/internal) $\times$ 2 tissues (peel/cortex) $\times 2$ fruit areas (top/ bottom) $\times 5$ replicates] and stored at $-80{ }^{\circ} \mathrm{C}$ for further analyses. Frozen samples were ground to a fine powder with $\mathrm{IKA}^{\circledR} \mathrm{A} 11$ basic mill (IKA ${ }^{\circledR}$ Works, Inc. Wilmington, NC) before analyses.

Volatile metabolite analysis. Volatile compounds were analyzed on $0.5 \mathrm{~g}$ of frozen peel and $1.0 \mathrm{~g}$ of frozen cortex powder as described by Rudell et al. (2009) and Lee et al. (2012a) with modifications. Vial headspace was analyzed using an Agilent $6890 \mathrm{~N}$ gas chromatograph coupled with a 5975B mass selective detector (Agilent Technologies, Palo Alto, CA) and an automated Gerstel multipurpose sampler (MPS; Gerstel, Baltimore, MD) equipped with a dynamic headspace sampler. Headspace vial temperature was maintained at $-1{ }^{\circ} \mathrm{C}$ using a cooled sample tray until sampling. At the beginning of the headspace sampling sequence, vials were vortexed at $1000 \mathrm{rpm}$ during incubation at $30{ }^{\circ} \mathrm{C}$ for $10 \mathrm{~min}$ before sampling. To sample, analyte was collected by sweeping $220 \mathrm{~mL}$ of $\mathrm{He}$ at $20 \mathrm{~mL} \cdot \mathrm{min}^{-1}$ through the headspace and then a $60 \mathrm{~mm}$ (length) $\times 6 \mathrm{~mm}$ (OD) glass tube (trap) containing $150 \mathrm{mg}$ of Tenax TA (60/80 mesh) (Supelco, St. Louis, MO) maintained at $30{ }^{\circ} \mathrm{C}$. After loading, water was removed from the trap by sweeping the sorption bed with $400 \mathrm{~mL}$ of $\mathrm{He}$ at $40 \mathrm{~mL} \cdot \mathrm{min}^{-1}$ while the trap was heated to $35{ }^{\circ} \mathrm{C}$. Traps were desorbed at $20 \mathrm{~mL} \cdot \mathrm{min}^{-1}$ with the inlet set in the solvent purge mode and purge pressure adjusted to the inlet pressure. The desorption temperature program started at $30{ }^{\circ} \mathrm{C}$ for $0.2 \mathrm{~min}$, increasing at $720{ }^{\circ} \mathrm{C} \cdot \mathrm{min}^{-1}$ to $300{ }^{\circ} \mathrm{C}$ and then holding for $3 \mathrm{~min}$. Desorbed analyte was collected on glass bead-filled liner maintained at $-145^{\circ} \mathrm{C}$ for the entire desorption period. Analyte was introduced into the GC column (HP Wax, Agilent) $(30 \mathrm{~m} \times 250 \mu \mathrm{m} \times 0.25 \mu \mathrm{m})$ by heating the liner to $150{ }^{\circ} \mathrm{C}$ at $16^{\circ} \mathrm{C} \cdot \mathrm{s}^{-1}$ and then to a final temperature of $300{ }^{\circ} \mathrm{C}$ at $12{ }^{\circ} \mathrm{C} \cdot \mathrm{s}^{-1}$, which was held for $3 \mathrm{~min}$. The helium carrier linear velocity was $40 \mathrm{~cm} \cdot \mathrm{s}^{-1}$. The injection split ratio was 1:5. The oven temperature was $35^{\circ} \mathrm{C}$ for $0.5 \mathrm{~min}$ and then increased to $300{ }^{\circ} \mathrm{C}$ at $12{ }^{\circ} \mathrm{C} \cdot \mathrm{min}^{-1}$. The detector was operated in the EI mode with transfer line, source, and quadrupole temperatures maintained at 250,150 , and $230{ }^{\circ} \mathrm{C}$, respectively. Mass spectra ranging from $\mathrm{m} / \mathrm{z}$ 30 to 600 were recorded.

Nonpolar metabolite extraction and analysis. Frozen $\left(-80{ }^{\circ} \mathrm{C}\right)$ peel powder $(0.5 \mathrm{~g})$ and cortex powder $(2.0 \mathrm{~g})$ were extracted and analyzed as described by Leisso et al. (2016) and Leisso et al. (2015). Target response data were acquired as indicated below ("Chromatographic mass spectral data extraction and pre-processing").

Polar metabolite extraction and analysis. Frozen peel powder $(0.1 \mathrm{~g})$ was weighed into $1.5 \mathrm{~mL}$ clear, $\mathrm{N}_{2}(l)$ cooled $\left(\approx-160{ }^{\circ} \mathrm{C}\right)$, screw-top microcentrifuge tubes containing $100 \mu \mathrm{L}$ of $1.0 \mathrm{~mm}$ (diameter) silicon carbide beads (BioSpec Products, Inc., Bartlesville, OK). $100 \mu \mathrm{L}$ of internal standard solution DL-Leucine $\left(1-{ }^{13} \mathrm{C}, 99 \%\right)$ (Cambridge Isotope Laboratories, Inc., Andover, MA) was added followed immediately by $600 \mu \mathrm{L}$ of cold chloroform, $300 \mu \mathrm{L}$ of cold methanol, and 300 of $\mu \mathrm{L}$ buffer ( 3 mM PIPES and EDTA at $\mathrm{pH}$ 7.2). The tubes were shaken vigorously for 2 min using a Mini Bead beater (BioSpec Products, Inc.) then centrifuged for $2 \mathrm{~min}$ at $6600 \mathrm{rpm}$. The upper methanol/buffer phase was then transferred to $13 \times 100 \mathrm{~mm}$ borosilicate test tubes placed on ice. The remaining chloroform phase was washed once with an additional $250 \mu \mathrm{L}$ of cold methanol and buffer and the bead beating/centrifugation process repeated compiling the methanol/ buffer phase. The test tubes containing the methanol/buffer partitions were then lyophilized using Speed Vac Concentrator (Savant Instruments, Inc., Farmingdale, NY) until dry $(\approx 3 \mathrm{~h})$. Sample residue was dissolved in 
250 of $\mu \mathrm{L}$ acetonitrile by sonicating until dissolved then filtered using $0.45 \mu \mathrm{m}$ PTFE before HPLC-MS analysis.

Samples were analyzed by injecting $10 \mu \mathrm{L}$ into a 1260 Infinity HPLC equipped with a 6520 Accurate Mass Quadrupole time-offlight (QTOF) detector and electrospray (ESI) source controlled by MassHunter Data Acquisition (B.05.00) software (Agilent Technologies, Santa Clara, CA). Resolution was performed using a SeQuant ${ }^{\circledR}$ ZIC $^{\circledR}$-pHILIC metal-free HPLC column $(100 \times$ $4.6 \mathrm{~mm}$; EMD Millipore Corporation, Billerica, MA) and a linear gradient of (A) 90:10 (v/v) acetonitrile (Fisher Scientific, Hampton, $\mathrm{NH}$ )/deionized water with $15 \mathrm{~mm}$ ammonium acetate for $2 \mathrm{~min}$ then increasing to $100 \%$ (B) 40:60 acetonitrile/deionized water with $15 \mathrm{~mm}$ ammonium acetate over $30 \mathrm{~min}$ and then held for $3 \mathrm{~min}$. The column temperature and flow rate were $40{ }^{\circ} \mathrm{C}$ and $0.4 \mathrm{~mL} \cdot \mathrm{min}^{-1}$, respectively. ESI ionization occurred with drying gas $\left(\mathrm{N}_{2}\right)$ temperature $=350{ }^{\circ} \mathrm{C}$, drying gas flow $=$ $11 \mathrm{~L} \cdot \mathrm{min}^{-1}$, nebulizer pressure $=35 \mathrm{psig}$, capillary voltage $=3000 \mathrm{~V}$, and fragmentor $=$ $-105 \mathrm{~V}$. Negative ions from 70 to $1200 \mathrm{~m} / \mathrm{z}$ were monitored at $1 \mathrm{scan} / \mathrm{s}$. Data were acquired in the MS mode using only the TOF as the mass analyzer.

Quality control. For all methods, two reference samples, comprising a bulk sample of 'Granny Smith' peel from fruit stored for 6 months in regular atmosphere at $1{ }^{\circ} \mathrm{C}$, were extracted and analyzed daily for all LC-MS and GC-MS analyses. The response of a selection of mass spectral tags (MSTs) representing both identified and unidentified metabolites was monitored to assure consistent extraction and instrument performance throughout the analysis period. In addition, the relative standard deviation of internal standard responses used for every method/ sample combination was required less than $10 \%$ within the whole experiment. Samples failing to meet that criterion were reextracted and analyzed.

Chromatographic mass spectral data extraction and pre-processing. The dilute polar (DP), concentrated polar (CP), NP, and $\mathrm{V}$ mzData sample sets were preprocessed using MZmine 2.20 (Pluskal et al., 2010) to generate a MST library for the DP and CP data and deconvolute, find, and quantify components from all data.

Raw data files were first converted to mzDATA. Then, a list of masses was generated for each dataset following the least noise removal. Single ion chromatograms using the accurate masses were generated for the DP, $\mathrm{CP}, \mathrm{NP}$, and $\mathrm{V}$ libraries using the following parameters (respectively): retention time (RT) windows $(0.2,0.2,0.2$, and 0.025 min), minimum peak height (100, 1000, 1000 , and 500 intensity units), and $\mathrm{m} / \mathrm{z}$ tolerance $(0.05,0.05,0.05$, and 0.6$)$.

Once the chromatograms were generated, the DP, CP, and NP samples were smoothed with a filter width of 7 . Deconvolution was accomplished using the "Local minimum search" algorithm using the following parameters for $\mathrm{DP}, \mathrm{CP}, \mathrm{NP}$, and $\mathrm{V}$ (respectively where four values are listed): chromatographic threshold $0 \%$, minimum RT search range 0.02 , minimum absolute height 100 , 1000,1000 , and 500, minimum peak top/ edge ratio 1 , peak duration range $0.02-3 \mathrm{~min}$ for DP, CP and NP, and 0.02-1 min for V.

Deconvoluted files were searched for metabolites in custom libraries created for each extraction/chromatographic method combination. Libraries containing metabolites were compiled and are continuously updated as new plant material or conditions (ontogeny, storage, phenotypic, etc.) using protocols outlined by Rudell et al. (2009). Compound identification was made based on retention time/index and mass spectral comparison with authentic standards for 143 metabolites (Supplemental File 1, see 'standard source' column D in the file and Rudell et al., 2005 and Rudell et al., 2011). Libraries were used to generate databases in MZmine consisting of RT and $\mathrm{m} / \mathrm{z}$ for each component. The custom database search tolerance and RT window were set at $0.05,0.05,0.05$, or $0.6(\mathrm{DP}, \mathrm{CP}, \mathrm{NP}$, or $\mathrm{V}) \mathrm{m} / \mathrm{z}$ and $0.4,0.4$, 0.4 , or $0.2 \mathrm{~min}$, respectively. The "Join aligner" algorithm was employed to reduce the likelihood of different peaks being compared among different samples using the following parameters for DP, CP, NP, and $\mathrm{V}$ chromatograms (where four values are listed): $\mathrm{M} / \mathrm{z}$ tolerance $(0.05,0.05,0.05$, and $0.6 \mathrm{~m} / \mathrm{z}$ ) with a scoring weight of 10 out of 100 , RT tolerance $(0.4,0.4,0.4$, and 0.1$)$ with a scoring weight of 90 out of 100 . Peaks from all aligned results were visually inspected to eliminate false identifications. For metabolites detectable in all samples using the dilute analysis, DP was used for results. For the remainder of the metabolites, results from $\mathrm{CP}$ were used.

Statistical analyses. Fruit size, color parameters, $\mathrm{I}_{\mathrm{AD}}$ decrease, percentage of weight loss, and $\mathrm{CO}_{2}$ production $\left(\mathrm{mL} \cdot \mathrm{kg}^{-1} \cdot \mathrm{h}^{-1}\right)$ were analyzed using the SAS proc GLM (SAS Institute, Cary, NC). The model was considered significant (with $P<0.05, P<0.01$, or $P<0.001)$ as determined using the Type III sums of squares test. Post-hoc means separations were performed using StudentNewman-Keuls significant difference (SNK) given $\alpha=0.05$. As all percentages were within $0 \%$ to $30 \%$ range, a square-root transformation was used to analyze them in accordance with the procedure outlined by Gomez and Gomez (1984) before analysis using proc GLM.

Both identified and tentatively or unidentified metabolites were compared from the peel and cortex tissue based on tree position or location of the tissue on the fruit. Before multivariate analyses of the metabolic profile data, area counts for each $x$-variable (metabolite) were mean-centered and then divided by the standard deviation resulting in a normalized data set for further analyses. Principal components analysis (PCA) was performed using Unscrambler X (Camo, Trondheim, Norway) to assess if the variance within the metabolome was attributed to the principal experimental factors (tree position and tissue position). Once this was established, PLS-DA was performed using Unscrambler X to allow "supervision" of the metabolomic model using $y$-variables (tree position, tissue position) where one or both contributed a major source of variance within the first three principal components of the PCA model. This apportioned more of the variance to the first three principal components with the intent of a more accurate assessment of associations among metabolites and between metabolites and response variables and, consequently ranking according to $x$-variables important to the projection (VIP; Wold, 1994). Student's $t$ tests (two tailed, heteroscedastic) were also performed on unnormalized data using the Microsoft (Redmond, WA) Excel (2010) " $t$ test" function (Supplemental File 1). Box plots were generated using Origin Pro 2016 (OriginLab Corp., Northampton, MA) as well as PCA and PLS-DA figures using results generated in the Unscrambler analyses.

\section{Results}

Maturity assessment. At harvest, fruit from the internal canopy were greener than the external fruit which were more yellow, also, often red blushed. After $24 \mathrm{~d}$ at room temperature, peel color was different between the canopy positions as indicated by differences of hue angle (Table 1). External fruit hue was lower, and color was less intense as indicated by the hue angle and $L$ values. $\mathrm{I}_{\mathrm{AD}}$ index was 0.26 lower for external at harvest (Fig. 1). External fruit $\mathrm{I}_{\mathrm{AD}}$ index decreased more rapidly than internal ones over the course of the experiment: 0.39 and 0.18 , respectively (Fig. 1). Fruit size and weight were not different between the two canopy positions at any point in the experiment, confirming that selected fruit were similar with respect to these nondestructive ripening metrics. Internal pears were noticeably more shriveled than external pears at $24 \mathrm{~d}$ which was also evident given the higher percent weight loss of the internal compared with the external fruit, $11.6 \%$ and $7.4 \%$, respectively (Table 1). $\mathrm{CO}_{2}$ and ethylene production was the same regardless of tree position (Table 1).

Metabolic profiling. Our profiling protocol detected and evaluated 844 metabolites in total, 498 in the cortex, and 706 in the peel (Supplemental File 1). Detected metabolites were of a wide range of volatility and polarity, including $\mathrm{V}$ esters, alcohols, and aldehydes, sugars, amino acids, organic acids, pectic acids, phenolics, isoprenoids, and isoprenoid conjugates, NP pigments, and triglycerides. Polymeric metabolites were not evaluated. 348 and 140 metabolites were found only in the peel or cortex, respectively, and 358 metabolites were detected in both tissues (Supplemental File 1).

Principal components analysis (PCA) scores of the peel data set indicated that both canopy position (PC1) and tissue region on the fruit (PC2) impacted the overall metabolome (Fig. 2A). However, cortex PCA 



postharvest at room temperature. Means separations were established with post hoc SNK test. Means in a column followed by the same letter are not statistically different at $P<0.05$.

\begin{tabular}{|c|c|c|c|c|c|c|c|}
\hline Position & L (lightness) & a (green-red) & b (blue-yellow & ${ }^{\circ}$ hue & Chroma & Ethylene & $\mathrm{CO}_{2}\left(\mathrm{~mL} \cdot \mathrm{kg}^{-1} \cdot \mathrm{h}^{-1}\right)$ \\
\hline External & $66.10 \mathrm{a}$ & $-9.67 \mathrm{a}$ & $40.97 \mathrm{a}$ & $103.28 \mathrm{~b}$ & $42.12 \mathrm{~b}$ & ND & 63.5 \\
\hline Internal & $62.02 \mathrm{~b}$ & $-16.85 b$ & $40.05 \mathrm{~b}$ & $112.82 \mathrm{a}$ & $43.46 \mathrm{a}$ & ND & 57.8 \\
\hline Significance & $* * *$ & $* * *$ & $*$ & $* * *$ & $* *$ & & NS \\
\hline Position & Wt (g) harvest day & $\mathrm{Wt}(\mathrm{g})+10 \mathrm{~d}$ & $\mathrm{Wt}(\mathrm{g})+14 \mathrm{~d}$ & $W t(g)+24 d$ & $\%$ wt lost in $10 \mathrm{~d}$ & $\%$ wt lost in $14 \mathrm{~d}$ & $\%$ wt lost in $24 \mathrm{~d}$ \\
\hline External & 284 & 274 & 267 & 263 & $3.32 \mathrm{~b}$ & $5.79 \mathrm{~b}$ & $7.37 \mathrm{~b}$ \\
\hline Internal & 261 & 247 & 237 & 231 & $5.22 \mathrm{a}$ & $9.13 \mathrm{a}$ & $11.60 \mathrm{a}$ \\
\hline Significance & NS & NS & NS & NS & $* * *$ & $* * *$ & $* * *$ \\
\hline
\end{tabular}

$* P<0.05, * * P<0.01, * * * P<0.001$, NS $=$ not significant.

$\mathrm{ND}=$ not detected; SNK $=$ Student-Newman-Keuls.

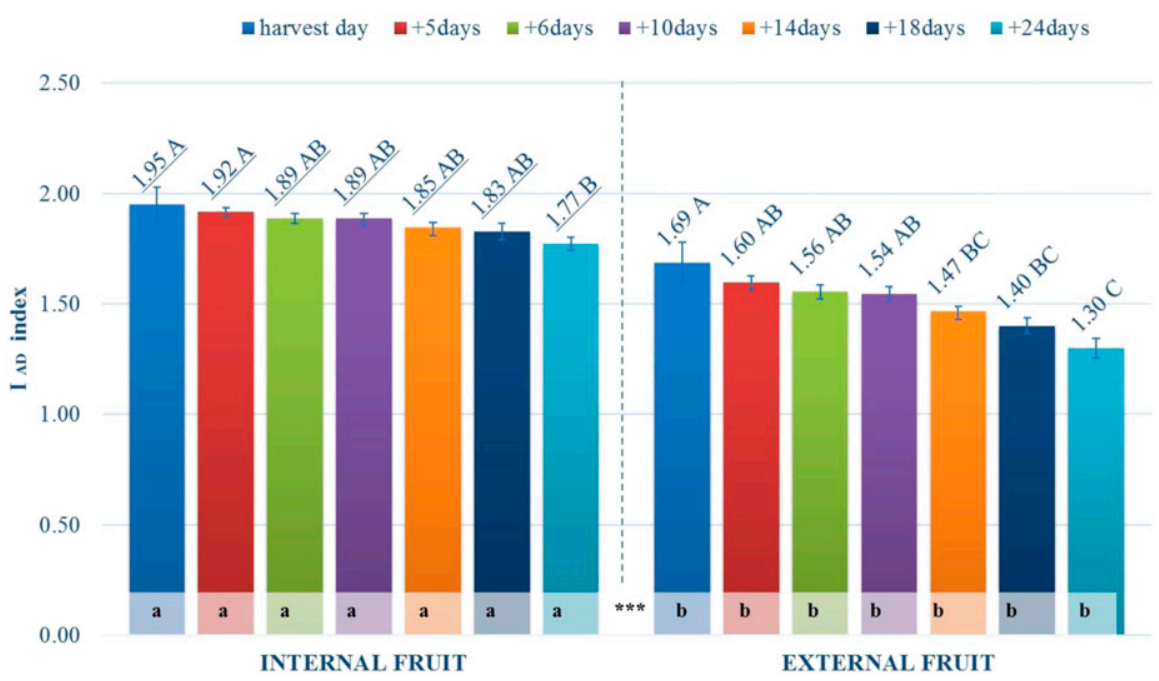

Fig. 1. $\mathrm{I}_{\mathrm{AD}}$ index for Internal and External 'd'Anjou' fruit after $24 \mathrm{~d}$ of postharvest at room temperature. Each column is the mean of 15 fruit \pm SE. $* P<0.05, * * P<0.01, * * * P<0.001$, n.s. = not significant. Mean separation was established with post hoc Student-Newman-Keuls test. Means followed by the same letter within the same canopy position are not statistically different for $P<0.001$ (underlined capital letters for internal and capital letters for external), while small letters discriminate between canopy positions within the same day of measurement.


Fig. 2. Principal components analysis scores plot of 'd'Anjou' pear fruit peel (A) and cortex (B) metabolome after $24 \mathrm{~d}$ at 20 to $25{ }^{\circ} \mathrm{C}$ following harvest from the internal or external canopy and sampled from the top or bottom of the fruit.

scores only indicated differences resulting from canopy position (Fig. 2B). PC3 did appear to be related to cortex tissue position but only represented $8 \%$ of the total variance. We chose to focus on the clearest sources of variance for further analyses. Once it was established which treatment categories had the greatest contribution to the variance within each data set, PLS-DA was used to maximize the variance attributed to these categories (response variable) and determine which metabolites were most closely linked with each category by determining each VIP score for a particular response variable (Fig. 3).

PLS-DA scores for the peel and cortex (Supplemental Fig. 1) show the same relationships among canopy positions and tissue as the PCA scores. The correlation loading plot for peel highlights a number of metabolites higher in the top or bottom of fruit and even more metabolites depending upon canopy position (Fig. 3). While the VIP scores clearly indicate this relationship with the combination of variables, the color coding by significance in the $t$ test illustrates the relationship where metabolites only different by canopy position (red) are on the horizontal poles of the plot and other metabolites differ by tissue position (green), or both (blue). Another group of metabolites was different between canopy positions only in one tissue position (yellow). These metabolites were not associated with either variable in the first three latent variables of the overall PLS-DA model. This model mainly accounts for variance based on differences between canopy positions in both tissue positions simultaneously and variance attributed to differences in only one tissue position would be diluted in this model.

Differences in metabolite levels included those typically related to fruit quality. Chlorophyll $\mathrm{a}$ and $\mathrm{b}$ levels were higher in fruit peel (Fig. 4) and cortex (Supplemental Fig. 2) of internal fruit. This was also reflected by the overall appearance where internal fruit was more green. The same differences were also observed with other chloroplastic compounds that may influence appearance or photosystem function. These included lutein and $\beta$-carotene (Fig. 4) as well as two thylakoid membrane components, monogalctosyldiacylglycerides (MGDG), which, like chlorophyll, were more prevalent in fruit harvested from the internal canopy (Fig. 4). Neoxanthin and violaxanthin levels were not different between canopy positions (data not shown).

Levels of other components typically associated with light protection were elevated in peel from external fruit. This included a peak representing a mixture of hyperin/isoquercetin in which internal peel contained very little and external contained more although quantities were more variable than internal peel (Fig. 5). Levels of other 

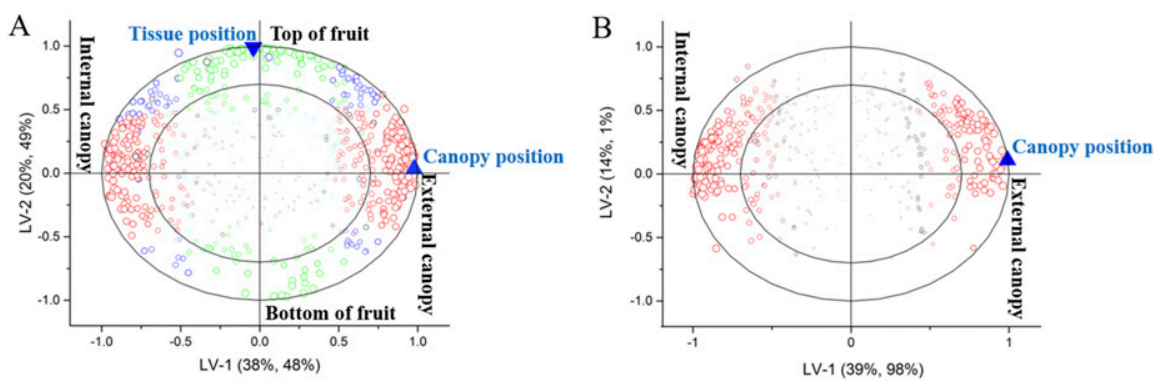

Fig. 3. PLS-DA correlations loading plots of metabolites detected in 'd'Anjou' pear fruit peel (A) and cortex (B) after $24 \mathrm{~d}$ at 20 to $25^{\circ} \mathrm{C}$ following harvest from the internal or external canopy and top or bottom (peel only). Larger circles indicate higher Variable's Importance in the Projection scores with respect to canopy position or tissue position. Red symbols indicate metabolites significantly different $(t$ test; $\alpha=0.05$ ) between canopy positions; green between tissue positions (peel only); blue significantly different in both categories (peel only); yellow different between canopy positions in only one tissue position (peel only).
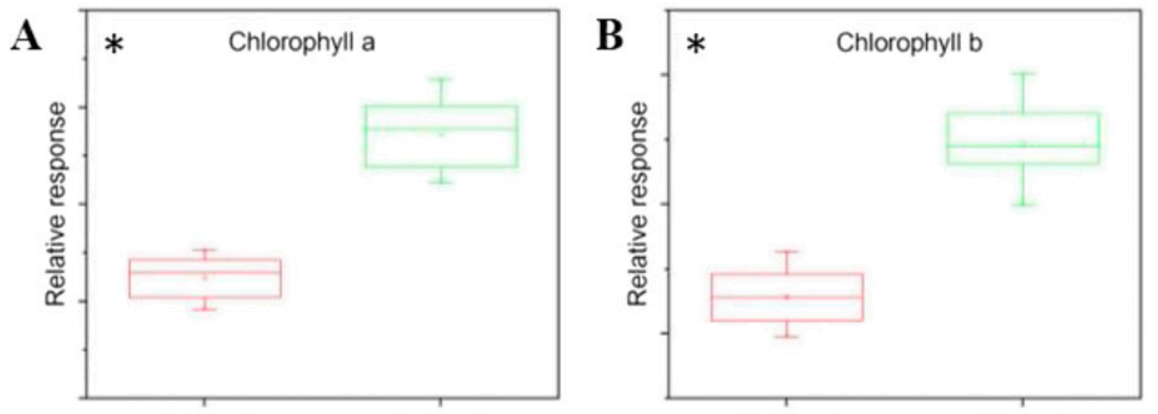

External

Internal
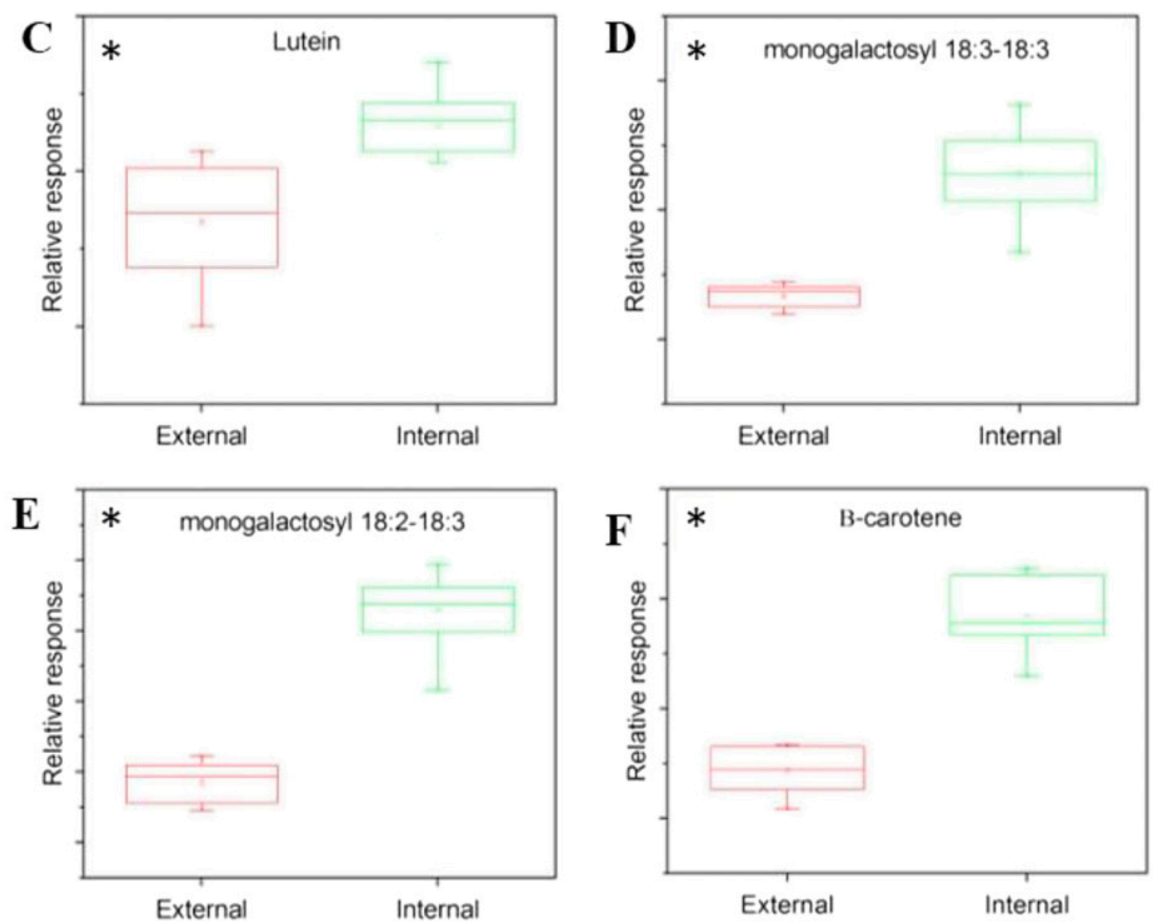

Fig. 4. Box plots of levels of photosystem metabolites (A-F) in 'd'Anjou' pear peel harvested from external or internal portions of the tree canopy. Boxes represent $25 \%$ to $75 \%$, bars represent 1.5 interquaternary range and horizontal lines designate the median. *Significant $(P \leq 0.05)$ based on $t$ test.

phenolics including cinnamic acids and arbutin were not different. Hyperin/isoquercetin was not detected in the cortex tissue (data not shown). Unlike with canopy position, in pear peel, ferulic acid, cinnamic acid, and arbutin levels were impacted by tissue position whereas hyperin/isoquercetin was not. Levels of these metabolites were higher in the top of the fruit (Fig. 5D, F, and $\mathrm{H})$. Tissue position impacted phenolics, but not other quality-related metabolism (data not shown).

Levels of compounds associated with pear flavor were different depending upon canopy position. Sucrose and sorbitol levels were higher in external fruit, whereas glucose and malic acid were higher in internal fruit. Fructose levels were not different (Fig. 6). Relative levels of these compounds were the same in the peel compared with the cortex (Supplemental Fig. 3).

Levels of V compounds responsible for both "ripe" and "unripe" or "green" odors were also impacted by tree position. 1-Hexanol and 2-methylpropanol levels were higher in external fruit peel, and 2-methylbutanol content was beginning to increase as indicated by the greater variance in the external than internal peel (Fig. 7). Significant increases in ester production associated with 'd'Anjou' ripening was not observed indicating that the fruit, while ripe in appearance, were not entirely ripe to a point typical for consuming this cultivar. Consequently, ester levels, when detected, were not different at this time point. "Green" or "unripe" flavor notes, including hexanal, E-2-hexenal, Z-3-hexenal, and E-2-pentenal, were lower in external than internal peel. Relative V levels in the cortex (Supplemental Fig. 4), when detected, were similar to those found in the peel (Fig. 7).

\section{Discussion}

External and sun-exposed fruit benefit actively from fruit and leaf photosynthesis from the beginning of their development and this could be an aspect that substantially influences differential physiology and metabolomics of external fruit relative to fruit in the shaded part of the canopy. Internal fruit are poor contributors to total yield; the mainly shade light regime may induce a shortage of carbohydrates and triggers a fruit abscission. All those hypotheses can reinforce the idea that a low density training system, such as open vase, leads to a huge variability in the fruit population in terms of different ripening behavior and fruit quality.

The $\mathrm{I}_{\mathrm{AD}}$ difference found between external and internal fruit at harvest and during $24 \mathrm{~d}$ ripening suggests a metabolomics approach and reveals variations in multiple metabolic pathways. The PCA scores plot for the peel tissue largely reflects differences in appearance where the comparison of internal and external fruit as well as the top and bottom tissue metabolomes reflected differences of color, $\mathrm{I}_{\mathrm{AD}}$, and "shrivel"/ water loss (Table 1; Fig. 1). Differences between cortex tissue from the top and bottom did not contribute enough to the overall variance to be a major component of the PCA model, whereas top vs. bottom of the fruit peel tissue were important in the PCA model (Fig. 2).

Given the differences in peel appearance, levels of metabolites that contribute to these differences would be expected. It is also evident that the disparity was much more widespread than a few metabolites and is, 

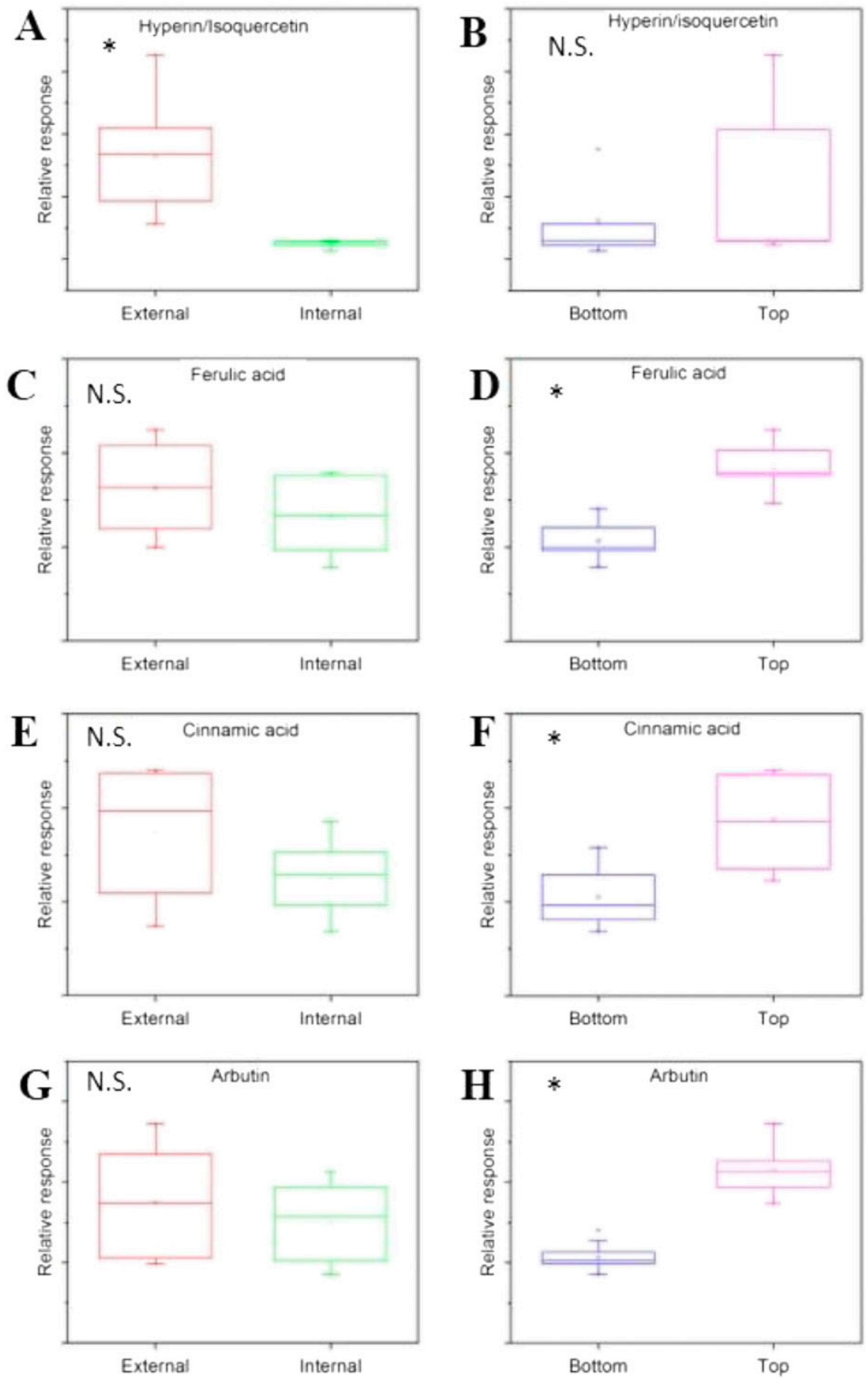

Fig. 5. Box plots of levels of phenolic metabolites in 'd'Anjou' pear peel harvested from external or internal portions of the tree canopy $(\mathbf{A}, \mathbf{C}, \mathbf{E}, \mathbf{G})$ or sampled from top or bottom of the fruit $(\mathbf{B}, \mathbf{D}, \mathbf{F}, \mathbf{H})$. Boxes represent $25 \%$ to $75 \%$, bars represent 1.5 interquaternary range and horizontal lines designate the median. *Significant $(P \leq 0.05)$ based on $t$ test.

instead, related to multiple metabolites from multiple pathways. This difference between internal and external fruit was also reflected in the underlying cortex tissue with respect to internal and external fruit (Supplemental Fig. 1). These experimental factors can alter ripening or maturity (Farhoomand et al., 1977; Kingston, 1993). While the link between ripening and light exposition and their effects on metabolites and pathways are not clarified yet.
Pears harvested from the external canopy developed a more yellow color after the ripening period than pears from the internal canopy. This visual observation is supported by the Chroma meter evaluation where hue $\left({ }^{\circ} \mathrm{h}\right)$ was lower for external fruit after the $24 \mathrm{~d}$ postharvest period (Table 1). As expected (Raffo et al., 2011), the relatively lower green color of external pear peel was accompanied by lower chl-a and chl-b levels (Fig. 4). Relative chlorophyll levels of the peel and cortex (Supplemental Fig. 2) also reflected $\mathrm{I}_{\mathrm{AD}}$ values at $24 \mathrm{~d}$. Chlorophyll degradation and peel degreening is a process characteristic of 'd'Anjou' ripening (Argenta et al., 2003), and it is considered one of the factors estimated by the DA meter as a maturity assessment tool (Bonora et al., 2013; Costa and Noferini, 2013; Ziosi et al., 2008). The DA meter was originally developed to assess peach maturity and ripening (Costa et al., 2009; Ziosi et al., 2008), and more recent evidence indicates it may also be useful for the same purpose on certain cultivars of pear including 'd'Anjou' (Gagliardi et al., 2014; Jajo et al., 2014; Mesa et al., 2016; Zhang et al., 2016). Previous evaluation of 'Abbé Fétel' maturation and ripening indicates that fruit with higher $\mathrm{I}_{\mathrm{AD}}$ values at harvest ripen less over 6 months of cold air storage (Musacchi et al., unpublished data).

Not only were chlorophyll levels different between canopy positions, but other chloroplastic metabolites were present at similar relative levels in both the peel and cortex including $\beta$-carotene and MGDG levels (Fig. 4; Supplemental Fig. 2). Overall, differences were indicative of transition of chloroplast to chromoplast associated with degreening (Pech et al., 2014). Xanthophylls, which were unchanged by tree position in this study, have photoprotective roles and accumulate in apple peel under high light conditions (Ma and Cheng, 2003; Merzlyak and Solovchenko, 2002; Merzlyak et al., 2008; Chen and Cheng, 2007). Although $\beta$-carotene levels increase with artificial light exposure in Asian pear (Pyrus pyrifolia) (Sun et al., 2014) and high light in apple peel (Felicetti and Schrader, 2009a; Ma and Cheng, 2003), lower levels in external ' $d$ 'Anjou' pear peel and cortex indicate that amounts are more linked with the chloroplast than ripening associated degreening. $\beta$-carotene levels decrease during apple ripening (Knee, 1971; Solovchenko et al., 2006) by supporting the light stress rather than chromoplastogenic role in a closely related species.

Galactolipids (MGDGs and DGDGs) are typically principal components of the thylakoid membrane (Robinson and Mant, 2009). Plastiglobules that form during chromoplastogenesis, a process characterized by degreening, contain very little galactolipids (Bréhélin and Kessler, 2008). Apple cortex tissue levels of MGDGs, but not DGDGs, can decrease with storage duration in apple (Picchioni et al., 1995). However, galactolipid levels increase overall during pepper fruit ripening (Whitaker, 1991). MGDG levels were the lowest in the external fruit peel which was least green, indicating that levels were associated with degreening and DGDG content was not impacted by tree position. These results indicated differences are likely not directly related to light interception but, rather, advanced maturity of external fruit compared with internal fruit under these conditions and within this time frame.

However, elevated levels of flavonol glycosides in this study may be indicative of the 

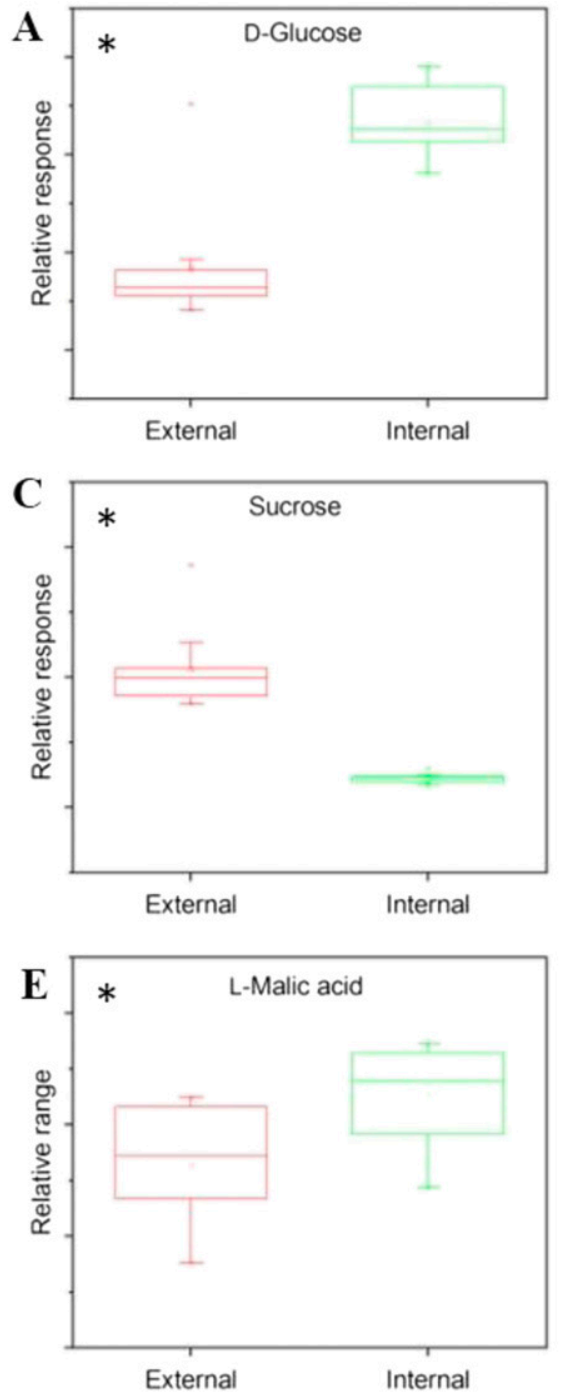

Fig. 6. Box plots of levels of sugar and organic acid metabolites (A-E) in 'd'Anjou' pear cortex harvested from external or internal portions of the tree canopy. Boxes represent $25 \%$ to $75 \%$, bars represent 1.5 interquaternary range and horizontal lines designate the median. ${ }^{*}$ Significant $(P \leq 0.05)$ based on $t$ test.

higher light environment in which external fruit resided than fruit maturity or ripeness. European pear peel contains both quercetin and isorhamnetin glycosides including quercetin 3-O-glucoside (isoquercetin) (Oleszek et al., 1994). Quercetin and isorhamnetin, among flavonol derivatives, may have a role in color transition and fruit quality (Fischer et al., 2007) that support their higher level in 'd'Anjou' external fruit in the present study. Light stress can trigger flavonol glycoside biosynthesis in leaves which may function in an antioxidant capacity or, more likely, for photoprotection (Treutter, 2005). Both Asian pear (Sun et al., 2014) and apple peel can produce more flavone glycoside with greater light ultraviolet-visible irradiation (Solovchenko and Schmitz-Eiberger, 2003; Workman, 1963) in a process that may confer greater photoprotection by absorbing excess light in wavelengths that might otherwise cause damage (Merzlyak and Solovchenko, 2002). Low levels of hyperin and rutin detected in 'd'Anjou' pear juice do not change

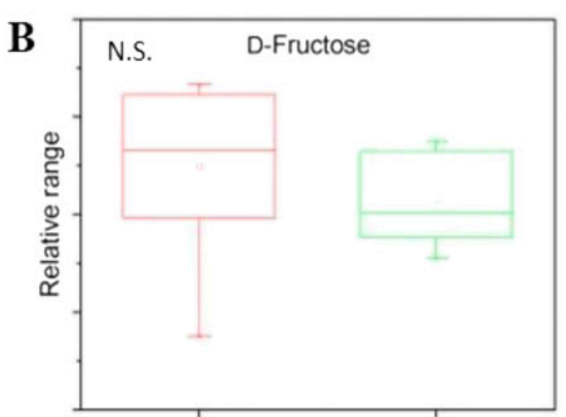

External

Internal

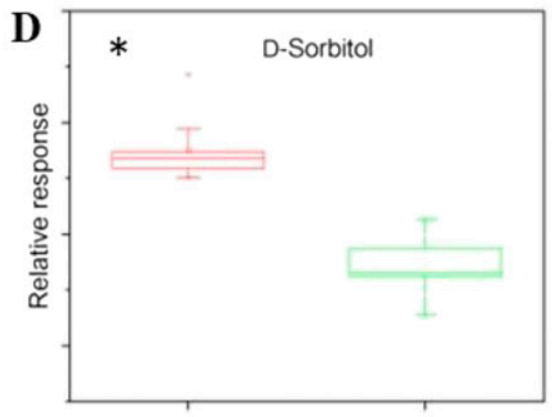

External

Internal
However, this, and other instances where metabolites are different based on position in the fruit, does highlight the importance of consistent or inclusive sampling with respect to regions selected for tissue sampling.

Light not only impacts obvious traits, such as appearance, it also translates into differences in levels of key quality-related metabolites. Sucrose, glucose, fructose, and sorbitol are chiefly responsible for sweetness and L-malic acid for tartness of European pears (Eccher Zerbini, 2002; Mesa et al., 2016). Sucrose and sorbitol accumulate in the fruit still attached to the tree, whereas glucose levels increase as starch is hydrolyzed (Mesa et al., 2016). After harvest, sucrose can be hydrolyzed to produce glucose and fructose as can be observed in apple peel and flesh during storage where sorbitol can also accumulate (Lee et al., 2012b; Rudell et al., 2008). L-malic acid is a principal postharvest carbon source for many Rosaceous fruits, including apple and pear (Ackermann et al., 1992; Eccher Zerbini, 2002); L-malic acid levels diminish over the storage period and relatively lower levels indicate advanced ripeness. Lower sucrose and D-sorbitol and higher L-malic acid levels all indicate that internal fruit were less ripe than external fruit after the $24 \mathrm{~d}$ ripening period. It is also possible that more exposed, external fruit were stronger sinks than internal shaded fruit, potentially enhancing their share of sucrose and sorbitol rich assimilate because of their proximity to more photosynthetically active regions of the branches.

Prior work with apple demonstrates the impact direct sunlight exposure may have on apple sugar and acid metabolism (Schrader et al., 2009). However, to what degree this is associated with light environment or maturity remains largely unsubstantiated. In apple, sunburn and high light injury can yield different sugar and acid levels within the region of the cortex just below the injury (Schrader et al., 2009). Sun-damaged pears were not considered in this study and sugar and acid levels were similar regardless of the cortex region indication tree position had the greatest impact. Postharvest artificial light treatments did not impact Asian pear cortex soluble solids or titratable acidity (Sun et al., 2014) or apple fruit peel sugar or acid levels (Rudell et al., 2008; Rudell and Mattheis, 2009) indicating that light alone may not impact these quality factors. However, sorbitol levels increase with duration of prestorage artificial ultraviolet-vis light exposure in apple (Rudell et al., 2008).

Differences in V compounds that contribute to aroma were particularly illustrative of fruit maturity differences between canopy positions. Levels of Vs most associated with "unripe" or "green" pears, hexanal, E-2hexenal, Z-3-hexenal, and E-2-pentenal, were highest in peel and cortex of internal fruit, while "ripe" pear Vs including 1hexanol, 2-methylpropanol, and 2-methylbutanol were higher in peel and cortex of external fruit (Fig. 7; Supplemental Fig. 4). 

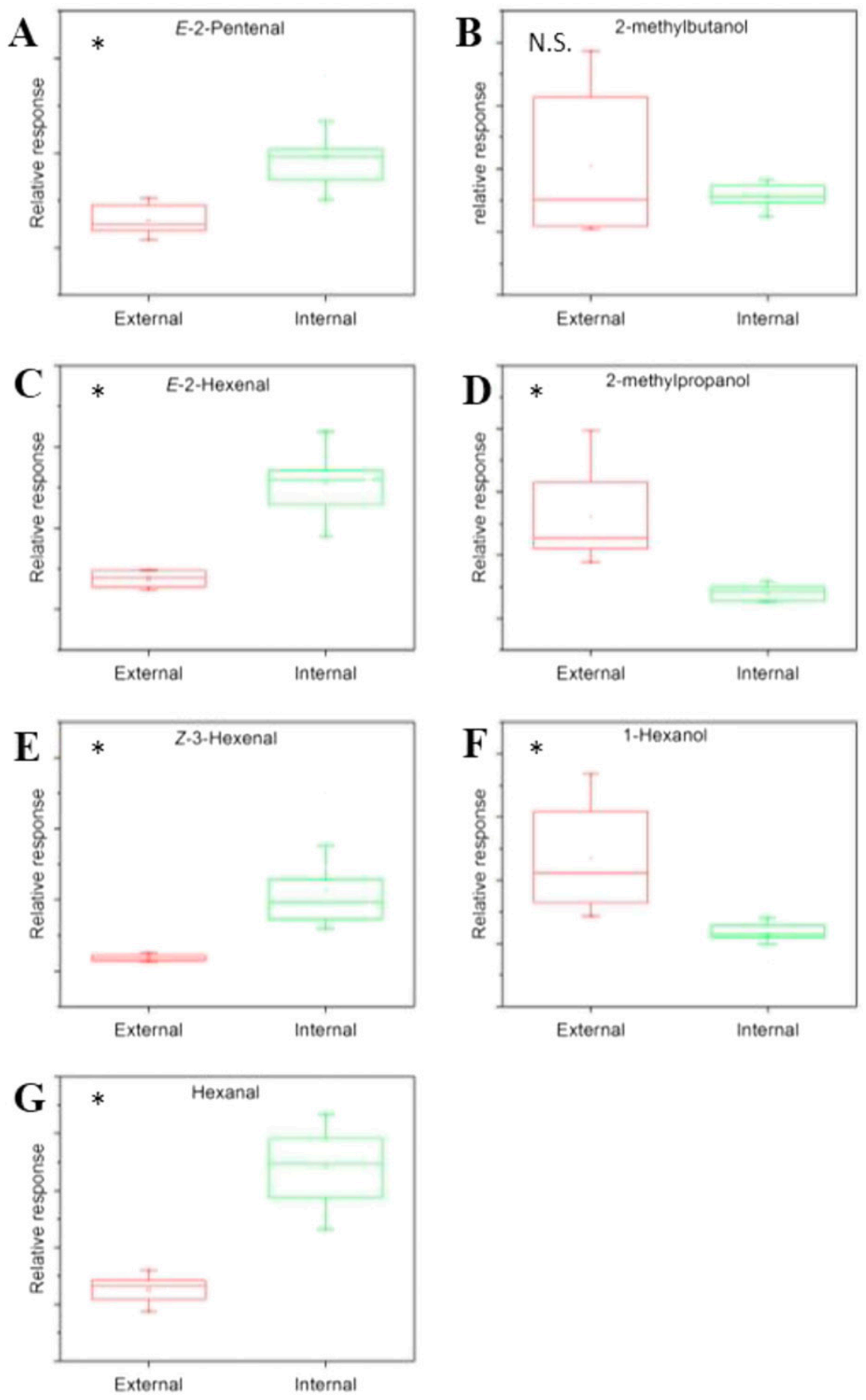

\section{Literature Cited}

Ackermann, J., M. Fischer, and R. Amado. 1992. Changes in sugars, acids, and amino acids during ripening and storage of apples (cv. Glockenapfel). J. Agr. Food Chem. 40(7): 1131-1134.

Ali, K., F. Maltese, A.M. Fortes, M.S. Pais, Y.H. Choi, and R. Verpoorte. 2011. Monitoring biochemical changes during grape berry development in Portuguese cultivars by NMR spectroscopy. Food Chem. 124(4):1760-1769.

Argenta, L.C., X. Fan, and J.P. Mattheis. 2003. Influence of 1-methylcyclopropene on ripening, storage life, and volatile production by d'Anjou cv. pear fruit. J. Agr. Food Chem. 51(13):3858-3864.

Fig. 7. Box plots of levels of "unripe" $(\mathbf{A}, \mathbf{C}, \mathbf{E}, \mathbf{G})$ and "ripe" $(\mathbf{B}, \mathbf{D}, \mathbf{F})$ volatile metabolites in 'd'Anjou' pear peel harvested from external or internal portions of the tree canopy. Boxes represent $25 \%$ to $75 \%$, bars represent 1.5 interquaternary range and horizontal lines designate the median. *Significant $(P \leq 0.05)$ based on $t$ test.

Apple peel typically produces much higher levels of $\mathrm{V}$ metabolites, including these, than cortex (Guadagni et al., 1971). Levels of these "unripe" Vs typically comprise more of the aroma profile in immature or unripe pears and apples, while the "ripe" Vs increase more with ripening and are far more prominent in the ripe pear profile (Argenta et al., 2003; Fellman et al., 2003). It is important to note that, though external fruit may be relatively more ripe than internal fruit, the $\mathrm{V}$ profile of the external fruit is not typical of a fully ripe pear as many compounds that are naturally present such as ethyl decadienoate and methyl decadienoate (Jennings et al., 1964; Shiota, 1990) were not detected. Ethyl decadienoate and methyl decadienoate can be detected in ripe 'd'Anjou' using the method outlined here. Again, although peel degreening might be indicative of a ripe

Aubert, C. and C. Milhet. 2007. Distribution of the volatile compounds in the different parts of a white-fleshed peach (Prunus persica L. Batsch). Food Chem. 102(1):375-384.

Bréhélin, C. and F. Kessler. 2008. The plastoglobule: A bag full of lipid biochemistry tricks. Photochem. Photobiol. 84:1388-1394.

Bonora, E., D. Stefanelli, and G. Costa. 2013 Nectarine fruit ripening and quality assessed using the index of absorbance difference. Intl. J. Agron. doi:10.1155/2013/242461.

Caldana, C., T. Degenkolbe, A. Cuadros-Inostroza, S. Klie, R. Sulpice, A. Leisse, D. Steinhauser, A.R. Fernie, L. Willmitzer, and M.A. Hannah. 2011. High-density kinetic analysis of the 
metabolomic and transcriptomic response of Arabidopsis to eight environmental conditions. Plant J. 67(5):869-884.

Carreno-Quintero, N., H.J. Bouwmeester, and J.J. Keurentjes. 2013. Genetic analysis of metabolome-phenotype interactions: From model to crop species. Trends Genet. 29(1): 41-50.

Chen, L.S. and L. Cheng. 2007. The sun-exposed peel of apple fruit has a higher photosynthetic capacity than the shaded peel. Funct. Plant Biol. 34(11):1038-1048.

Chen, P.M. and W.M. Mellenthin. 1981. Effects of harvest date on ripening capacity and postharvest life of 'd'Anjou' pears. J. Amer. Soc. Hort. Sci. 106:38-42.

Costa, G., M. Noferini, G. Fiori, and P. Torrigiani. 2009. Use of Vis/NIR spectroscopy to assess fruit ripening stage and improve management in post-harvest chain. GBS J. Fresh Produce $3: 35-41$.

Costa, G. and M. Noferini. 2013. Use of nondestructive devices as a decision support system for fruit quality enhancement. Acta Hort. 998:103-116.

Doerflinger, F.C., W.B. Miller, J.F. Nock, and C.B. Watkins. 2015. Relationships between starch pattern indices and starch concentrations in four apple cultivars. Postharvest Biol. Technol. 110:86-95.

Eccher Zerbini, P. 2002. The quality of pear fruit. Acta Hort. 596:805-810.

Farhoomand, M.B., M.E. Patterson, and C.L. Chu. 1977. The ripening pattern of 'Delicious' apples in relation to position on the tree. J. Amer. Soc. Hort. Sci. 102:771-774.

Felicetti, D.A. and L.E. Schrader. 2009a. Changes in pigment concentrations associated with sunburn browning of five apple cultivars. I. Chlorophylls and carotenoids. Plant Sci. 176:78-83.

Felicetti, D.A. and L.E. Schrader. 2009b. Changes in pigment concentrations associated with sunburn browning of five apple cultivars. II. Phenolics. Plant Sci. 176:84-89.

Fellman, J.K., D.R. Rudell, D.S. Mattinson, and J.P. Mattheis. 2003. Relationship of harvest maturity to flavor regeneration after CA storage of 'Delicious' apples. Postharvest Biol. Technol. 27:39-51.

Fiehn, O. 2002. Metabolomics-the link between genotypes and phenotypes. Plant Mol. Biol. 48 (1-2):155-171.

Fischer, T.C., C. Gosch, J. Pfeiffer, H. Halbwirth, C. Halle, K. Stich, and G. Forkmann. 2007. Flavonoid genes of pear (Pyrus communis). Trees (Berl.) 21(5):521-529.

Gagliardi, F., S. Serra, V. Ancarani, D. Bucci, L. Piccinini, M. Noferini, S. Musacchi, and G. Costa. 2014. Preliminary results on CV.'Abbé Fétel' productivity and fruit quality in relation to tree architecture. Acta Hort. 1058:151-158.

Gomez, K.A. and A.A. Gomez. 1984. Statistical procedures for agricultural research. Wiley, New York, NY.

Guadagni, D.G., J.L. Bomben, and J.S. Hudson. 1971. Factors influencing the development of aroma in apple peels. J. Sci. Food Agr. 22:110-115.

Hiwasa, K., Y. Kinugasa, S. Amano, A. Hashimoto, R. Nakano, A. Inaba, and Y. Kubo. 2003. Ethylene is required for both the initiation and progression of softening in pear (Pyrus communis L.) fruit. J. Expt. Bot. 54(383):771-779.

Jajo, A., M.A. Rahim, S. Serra, F. Gagliardi, N.K. Jajo, S. Musacchi, G. Costa, C. Bonghi, and L. Trainotti. 2014. Impact of tree training system, branch type and position in the canopy on the ripening homogeneity of 'Abbé Fétel' pear fruit. Tree Genet. Genomes 10(5):1477-1488.
Jennings, W.G., R.K. Creveling, and D.E. Heinz. 1964. Volatile esters of Bartlett pear. IV. Esters of trans-2,cis-4-decadienoic acid. J. Food Sci. 29:730-734

Kappel, F. and G.H. Neilsen. 1994. Relationship between light microclimate, fruit growth, fruit quality, specific leaf weight and $\mathrm{N}$ and $\mathrm{P}$ content of spur leaves of 'Bartlett' and 'Anjou' pear. Sci. Hort. 59(3-4):187-196.

Khemira, H., P.B. Lombard, D. Sugar, and A.N. Azarenko. 1993. Hedgerow orientation affects canopy exposure, flowering, and fruiting of 'Anjou' pear trees. HortScience 28:984-987.

Kingston, C.M. 1993. Maturity indices for apple and pear. Hort. Rev. 13:407-439.

Knee, M. 1971. Anthocyanin, carotenoid, and chlorophyll changes in the peel of Cox's Orange Pippin apples during ripening on and off the tree. J. Expt. Bot. 23:184-196.

Lalel, H.J.D., Z. Singh, and S.C. Tan. 2003. Distribution of aroma volatile compounds in different parts of mango fruit. J. Hort. Sci. Biotechnol. 78(2):131-138.

Lee, J., J.P. Mattheis, and D.R. Rudell. 2012a. Antioxidant treatment alters metabolism associated with internal browning in 'Braeburn' apples during controlled atmosphere storage. Postharvest Biol. Technol. 68:32-42.

Lee, J., D.R. Rudell, P.J. Davies, and C.B. Watkins. 2012 b. Metabolic changes in 1-methylcyclopropene (1-MCP)-treated 'Empire' apple fruit during storage. Metabolomics 8:742-753.

Le Lezec, M. and A. Belouin. 1994. Test de regression de 1'amidon des poires. Arboriculture Fruitiere 474:34-35.

Leisso, R.S., D.A. Buchanan, J. Lee, J.P. Mattheis, C. Sater, I. Hanrahan, and M.L. Hertog. 2015. Chilling-related cell damage of apple (Malus $\times$ domestica Borkh.) fruit cortical tissue impacts antioxidant, lipid and phenolic metabolism. Physiol. Plant. 153(2):204-220.

Leisso, R.S., N.E. Gapper, J.P. Mattheis, N.L. Sullivan, C.B. Watkins, J.J. Giovannoni, R.J. Schaffer, J.W. Johnston, I. Hanrahan, M.L. Hertog, and B.M. Nicolai. 2016. Gene expression and metabolism preceding soft scald, a chilling injury of 'Honeycrisp' apple fruit. BMC Genomics 17(1):798.

Lombardo, V.A., S. Osorio, J. Borsani, M.A. Lauxmann, C.A. Bustamante, C.O. Budde, and M.F. Drincovich. 2011. Metabolic profiling during peach fruit development and ripening reveals the metabolic networks that underpin each developmental stage. Plant Physiol. 157(4):1696-1710.

Ma, F. and L. Cheng. 2003. The sun-exposed peel of apple fruit has higher xanthophyll cycledependent thermal dissipation and antioxidants of the ascorbate-glutathione pathway than the shaded peel. Plant Sci. 165:819-827.

McGuire, R. 1992. Reporting of objective color measurements. HortScience 27:1254-1255.

Merzlyak, M.N. and A.E. Solovchenko. 2002. Photostability of pigments in ripening apple fruit: A possible photoprotective role of carotenoids during plant senescence. Plant Sci. 163(4):881-888.

Merzlyak, M.N., T.B. Melø, and K.R. Naqvi. 2008. Effect of anthocyanins, carotenoids, and flavonols on chlorophyll fluorescence excitation spectra in apple fruit: Signature analysis, assessment, modelling, and relevance to photoprotection. J. Expt. Bot. 59:349-359.

Mesa, K., S. Serra, A. Masia, F. Gagliardi, D. Bucci, and S. Musacchi. 2016. Seasonal trends of starch and soluble carbohydrates in fruits and leaves of 'Abbé Fétel' pear trees and their relationship to fruit quality parameters. Sci. Hort. 211:60-69.
Moco, S., R.J. Bino, O. Vorst, H.A. Verhoeven, J. de Groot, T.A. van Beek, and C.R. De Vos. 2006. A liquid chromatography-mass spectrometrybased metabolome database for tomato. Plant Physiol. 141(4):1205-1218.

Nashima, K., T. Shimizu, C. Nishitani, T. Yamamoto, H. Takahashi, M. Nakazono, and S. Matsumoto. 2013. Microarray analysis of gene expression patterns during fruit development in European pear (Pyrus communis). Sci. Hort. 164: 466-473.

Neri, D., G. Savini, F. Massetani, V. Giorgi, and P. Sabbatini. 2008. Pear pruning and training for economically sustainable production. Acta Hort. 800:747-754.

Núñez-Delicado, E., M. Serrano-Megías, A.J. Pérez-López, and J.M. López-Nicolás. 2005 Polyphenol oxidase from Dominga table grape. J. Agr. Food Chem. 53:6087-6093

Oikawa, A., T. Otsuka, R. Nakabayashi, Y. Jikumaru, K. Isuzugawa, H. Murayama, and K. Shiratake. 2015. Metabolic profiling of developing pear fruits reveals dynamic variation in primary and secondary metabolites, including plant hormones. PLoS One 10(7):e0131408.

Oleszek, W., M.J. Amiot, and S.Y. Aubert. 1994. Identification of some phenolics in pear fruit. J. Agr. Food Chem. 42(6):1261-1265.

Oms-Oliu, G., I. Odriozola-Serrano, and O. MartinBelloso. 2012. Using metabolomics to improve the quality of postharvest fruit, p. 207-214. In: D. Hemming (ed.). Plant sciences reviews 2012. CABI, UK.

Palmer, J.W. 1988. Annual dry matter production and partitioning over the first 5 years of a bed system of Crispin/M. 27 apple trees at four spacings. J. Appl. Ecol. 25(2):569-578.

Pech, J.C., M. Bouzayen, and A. Latché. 2014 Cellular, metabolic and molecular aspects of chromoplast differentiation in ripening fruit, p. 28-47. In: P. Nath, M. Bouzayen, A.K. Mattoo, and J.C. Pech (eds.). Fruit ripening: Physiology, signaling and genomics. CABI, UK.

Pedreschi, R., C. Franck, J. Lammertyn, A. Erban, J. Kopka, M. Hertog, B. Verlinden, and B. Nicolai. 2009. Metabolic profiling of 'Conference' pears under low oxygen stress. Postharvest Biol. Technol. 51(2):123-130.

Picchioni, G.A., A.E. Watada, W.S. Conway, B.D. Whitaker, and C.E. Sams. 1995. Phospholipid, galactolipid, and steryl lipid composition of apple fruit cortical tissue following postharvest $\mathrm{CaCl} 2$ infiltration. Phytochemistry 39:763769.

Pluskal, T., S. Castillo, A. Villar-Briones, and M. Oresic. 2010. MZmine 2: Modular frame- work for processing, visualizing, and analyzing mass spectrometry-based molecular profile data. BMC Bioinformatics 11(1):395-405.

Raffo, M.D., N.M. Ponce, G.O. Sozzi, A.R. Vicente, and C.A. Stortz. 2011. Compositional changes in 'Bartlett' pear (Pyrus communis L.) cell wall polysaccharides as affected by sunlight conditions. J. Agr. Food Chem. 59(22):1215512162.

Reuscher, S., K. Isuzugawa, M. Kawachi, A. Oikawa, and K. Shiratake. 2014. Comprehensive elemental analysis of fruit flesh from European pear 'La France' and its giant fruit bud mutant indicates specific roles for $B$ and $\mathrm{Ca}$ in fruit development. Sci. Hort. 176: 255-260.

Reuscher, S., Y. Fukao, R. Morimoto, S. Otagaki, A. Oikawa, K. Isuzugawa, and K. Shiratake. 2016. Quantitative proteomics based reconstruction and identification of metabolic pathways and membrane transport proteins related to sugar accumulation in developing fruits of 
pear (Pyrus communis). Plant Cell Physiol. 57 (3):505-518.

Robinson, C. and A. Mant. 2009. Biogenesis of the thylakoid membrane. Annu. Plant Rev. 13:180-331.

Rudell, D.R., D.S. Mattinson, J.P. Mattheis, and J.K. Fellman. 2000. The progression of ethylene production and respiration in the tissues of ripening 'Fuji' apple fruit. HortScience 35: 1300-1303.

Rudell, D.R., J.P. Mattheis, and J.K. Fellman. 2005. Relationship of superficial scald development and $\alpha$-farnesene oxidation to reactions of diphenylamine and diphenylamine derivatives in cv. Granny Smith apple peel. J. Agr. Food Chem. 53:8382-8389.

Rudell, D.R., J.P. Mattheis, and E.A. Curry. 2008. Prestorage ultraviolet-white light irradiation alters apple peel metabolome. J. Agr. Food Chem. 56(3):1138-1147.

Rudell, D.R. and J.P. Mattheis. 2009. Superficial scald development and related metabolism is modified by postharvest light irradiation. Postharvest Biol. Technol. 51(2):174-182.

Rudell, D.R., J.P. Mattheis, and M.L. Hertog. 2009. Metabolomic change precedes apple superficial scald symptoms. J. Agr. Food Chem. 57:8459-8466.

Rudell, D.R., D.A. Buchanan, R.S. Leisso, B.D. Whitaker, J.P. Mattheis, Y. Zhu, and V. Varanasi. 2011. Ripening, storage temperature, ethylene action, and oxidative stress alter apple peel phytosterol metabolism. Phytochemistry 72:1328-1340.

Schrader, L.E., J. Zhang, J. Sun, J. Xu, D.C. Elfving, and C. Kahn. 2009. Postharvest changes in internal fruit quality in apples with sunburn browning. J. Amer. Soc. Hort. Sci. 134(1): $148-155$.

Shiota, H. 1990. Changes in the volatile composition of La France pear during maturation. J. Sci. Food Agr. 52:421-429.

Solovchenko, A. and M. Schmitz-Eiberger. 2003. Significance of skin flavonoids for UV Bprotection in apple fruits. J. Expt. Bot. 54: 1977-1984.

Solovchenko, A.E., O.V. Avertcheva, and M.N. Merzlyak. 2006. Elevated sunlight promotes ripening-associated pigment changes in apple fruit. Postharvest Biol. Technol. 40:183-189.

Spanos, G.A. and R.E. Wrolstad. 1992. Phenolics of apple, pear, and white grape juices and their changes with processing and storage. A review. J. Agr. Food Chem. 40(9):1478-1487.

Stewart, D., G.J. McDougall, J. Sungurtas, S. Verrall, J. Graham, and I. Martinussen. 2007. Metabolomic approach to identifying bioactive compounds in berries: Advances toward fruit nutritional enhancement. Mol. Nutr. Food Res. 51(6):645-651.

Sun, Y., M. Qian, R. Wu, Q. Niu, Y. Teng, and D. Zhang. 2014. Postharvest pigmentation in red Chinese sand pears (Pyrus pyrifolia Nakai) in response to optimum light and temperature. Postharvest Biol. Technol. 91:64-71.

Torres, C.A., A. Sepulveda, J. Gonzalez-Talice, J.A. Yuri, and I. Razmilic. 2013. Fruit water relations and osmoregulation on apples (Malus domestica Borkh.) with different sun exposures and sun-injury levels on the tree. Sci. Hort. 161:143-152.
Treutter, D. 2005. Significance of flavonoids in plant resistance and enhancement of their biosynthesis. Plant Biol. 7(6):581-591.

Whitaker, B.D. 1991. Growth conditions and ripening influence plastid and microsomal membrane lipid composition in bell pepper fruit. J. Amer. Soc. Hort. Sci. 116:525-533.

Wold, S. 1994. PLS for multivariate linear modeling. In: H. Van de Watterbeemd (ed.). QSAR: Chemometric methods in molecular design. Methods and principles in medicinal chemistry. Verlag-Chemie, Weinheim, Germany.

Workman, M. 1963. Color and pigment changes in Golden Delicious and Grimes Golden apples. J. Amer. Soc. Hort. Sci. 83:149-161.

Wünsche, J.N., A.N. Lakso, T.L. Robinson, F. Lenz, and S.S. Denning. 1996. The bases of productivity in apple production systems: The role of light interception by different shoot types. J. Amer. Soc. Hort. Sci. 121:886-893.

Zhang, J., X. Wang, O. Yu, J. Tang, X. Gu, X. Wan, and C. Fang. 2010. Metabolic profiling of strawberry (Fragaria $\times$ ananassa Duch.) during fruit development and maturation. J. Expt. Bot. 62(3):1-16.

Zhang, J., S. Serra, R.S. Leisso, and S. Musacchi. 2016. Effect of light microclimate on the quality of 'd'Anjou' pears in mature opencentre tree architecture. Biosyst. Eng. 141:111.

Ziosi, V., M. Noferini, G. Fiori, A. Tadiello, L. Trainotti, G. Casadoro, and G. Costa. 2008. A new index based on vis spectroscopy to characterize the progression of ripening in peach fruit. Postharvest Biol. Technol. 49:319-329. 

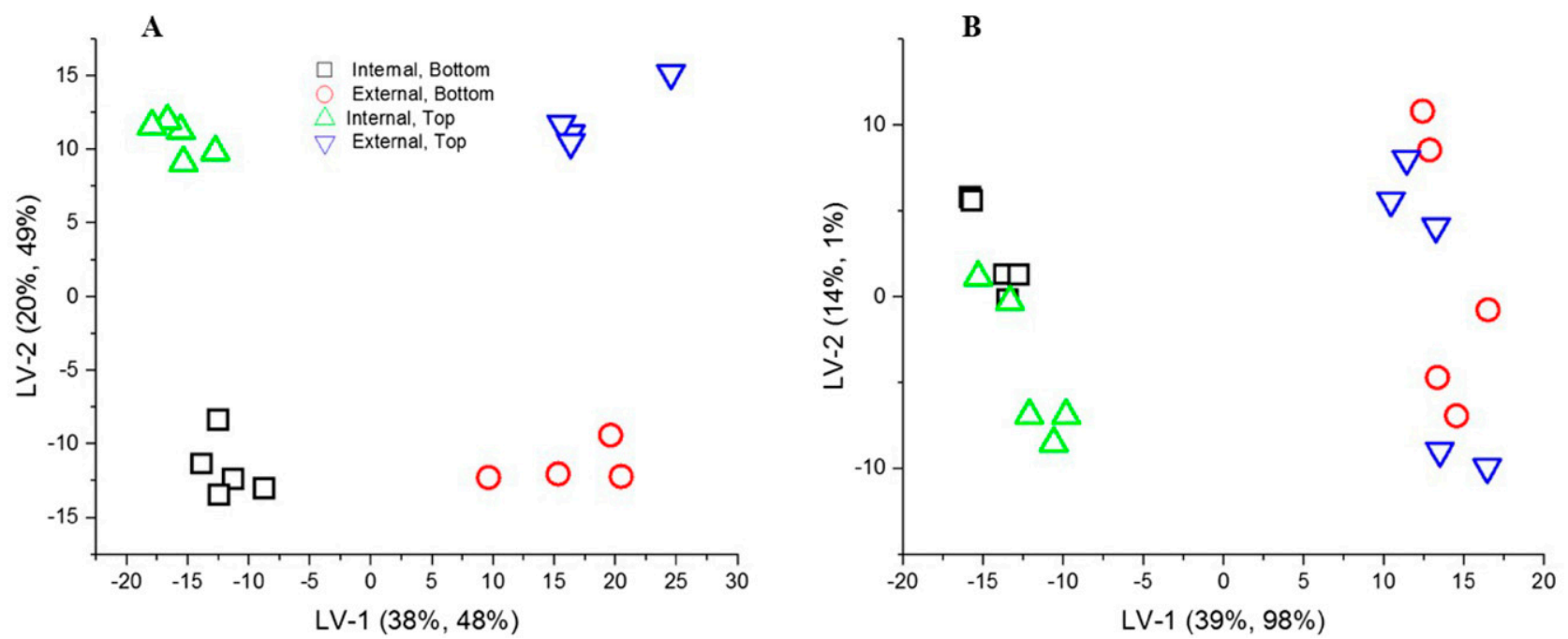

Supplemental Fig. 1. PLS scores plot of comparing differences of 'd'Anjou' pear fruit peel (A) and cortex (B) metabolome after $24 \mathrm{~d}$ at 20 to $25^{\circ} \mathrm{C}$ following harvest from the internal or external canopy and sampled from the top or bottom of the fruit. Response variables supervising the peel (A) PLS analysis include both tree position and tissue position while only tree position was used for the cortex model (B). 

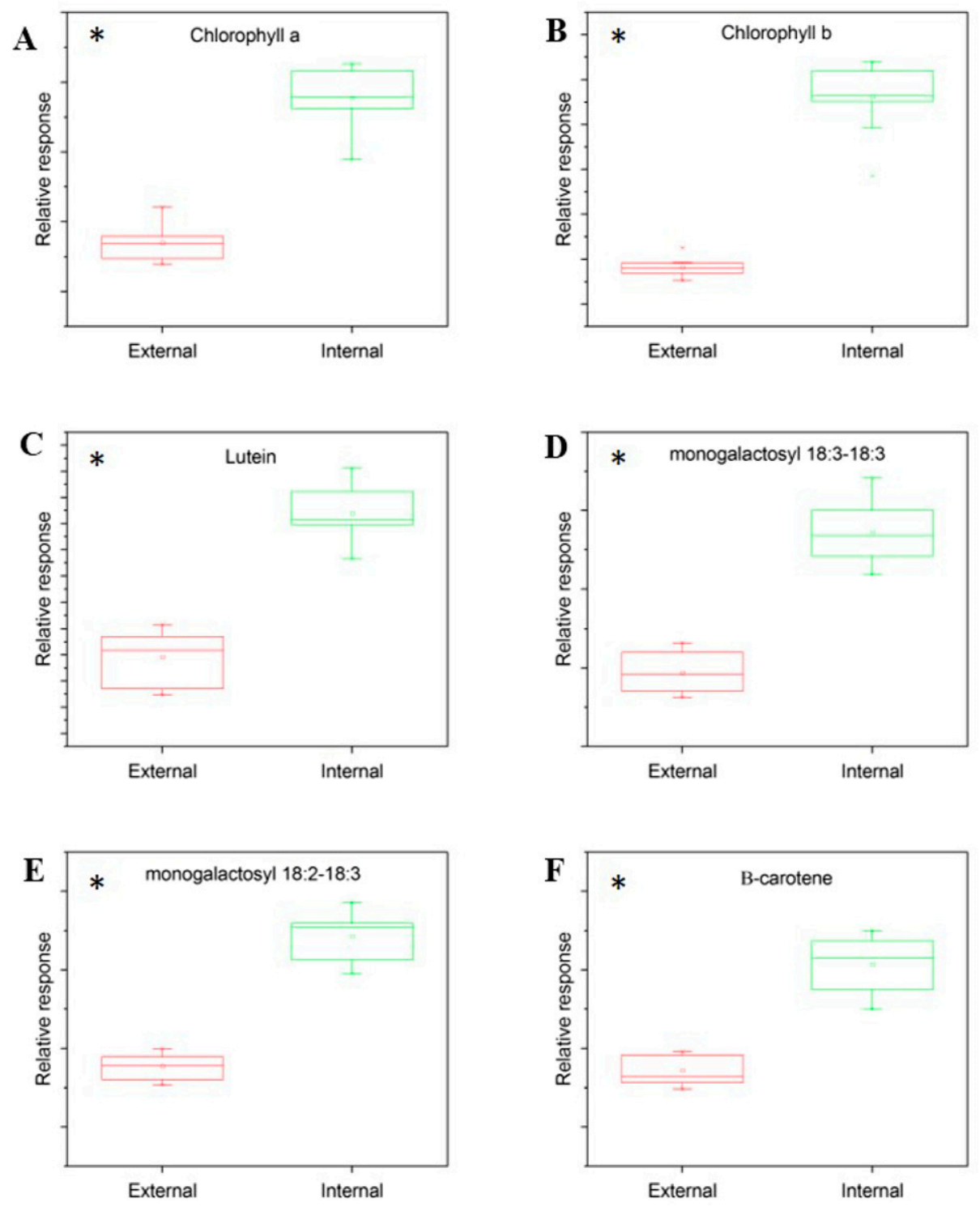

Supplemental Fig. 2. Box plots of levels of photosystem metabolites in 'd'Anjou' pear cortex harvested from external or internal portions of the tree canopy. Boxes represent $25 \%$ to $75 \%$, bars represent 1.5 inter-quaternary range and horizontal lines designate the median. $*$ Significant $(P \leq 0.05)$ based on $t$ test. 

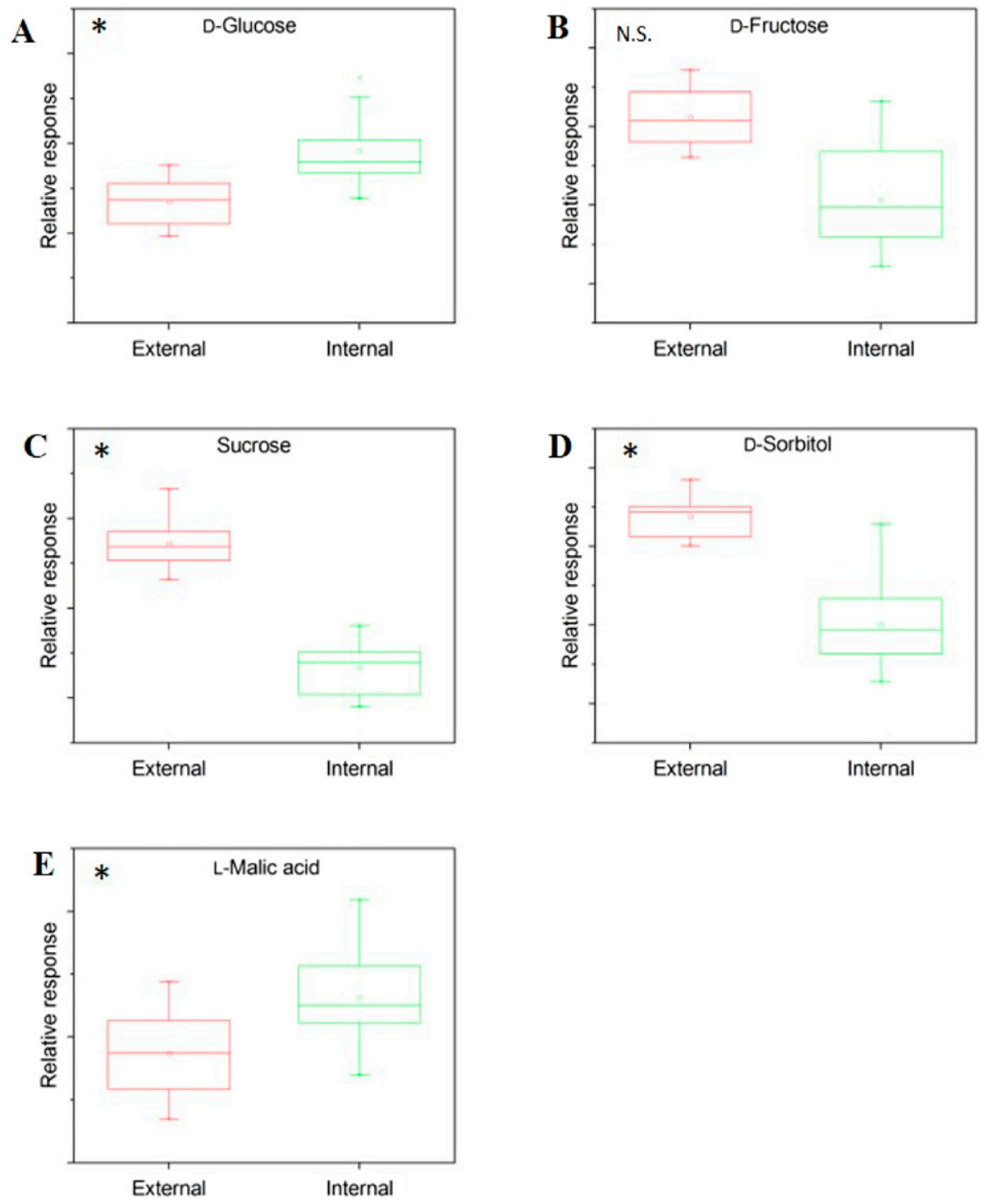

Supplemental Fig. 3. Box plots of levels of sugar and organic acid metabolites in 'd'Anjou' pear peel harvested from external or internal portions of the tree canopy. Boxes represent $25 \%$ to $75 \%$, bars represent 1.5 inter-quaternary range and horizontal lines designate the median. * Significant $(P \leq 0.05)$ based on $t$ test. 

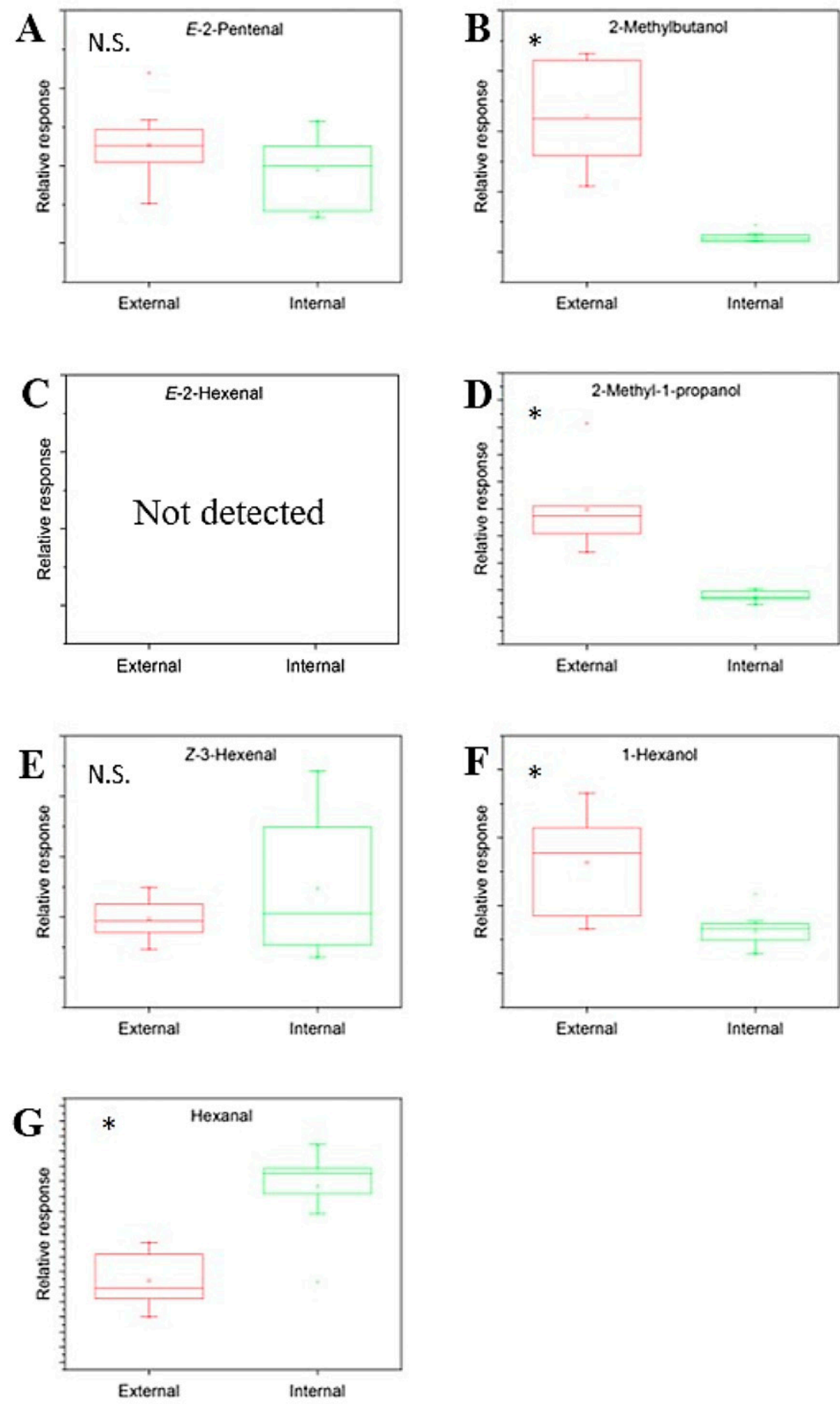

Supplemental Fig. 4. Box plots of levels of "unripe" $(\mathbf{A}, \mathbf{C}, \mathbf{E}, \mathbf{G})$ and "ripe" (B, D, F) volatile metabolites in 'd'Anjou' pear cortex harvested from external or internal portions of the tree canopy. Boxes represent $25 \%$ to $75 \%$, bars represent 1.5 inter-quaternary range and horizontal lines designate the median. *Significant $(P \leq 0.05)$ based on $t$ test. 

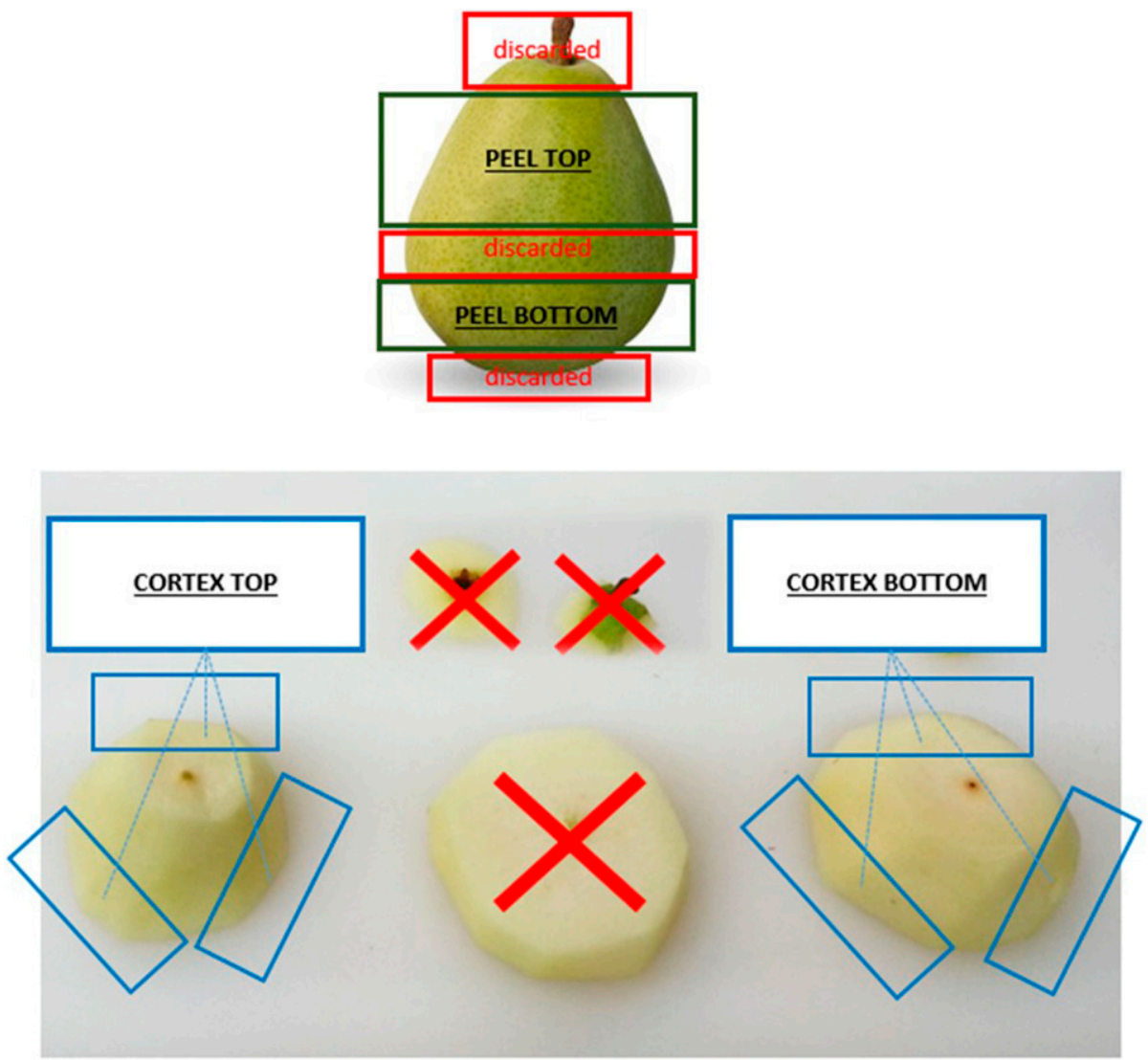

Supplemental Fig. 5. Details of how the sample was collected, cut and processed for metabolomics analyses. 